\title{
Pathophysiology of Crohn's disease inflammation and recurrence
}

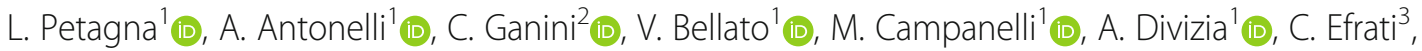

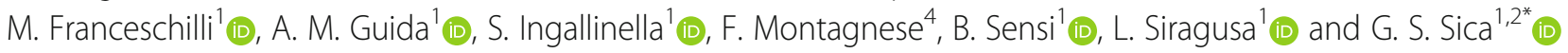

\begin{abstract}
Chron's Disease is a chronic inflammatory intestinal disease, first described at the beginning of the last century. The disease is characterized by the alternation of periods of flares and remissions influenced by a complex pathogenesis in which inflammation plays a key role. Crohn's disease evolution is mediated by a complex alteration of the inflammatory response which is characterized by alterations of the innate immunity of the intestinal mucosa barrier together with a remodeling of the extracellular matrix through the expression of metalloproteins and increased adhesion molecules expression, such as MAcCAM-1. This reshaped microenvironment enhances leucocytes migration in the sites of inflammation, promoting a $T_{H} 1$ response, through the production of cytokines such as IL12 and TNF-a. IL-12 itself and IL-23 have been targeted for the medical treatment of CD. Giving the limited success of medical therapies, the treatment of the disease is invariably surgical. This review will highlight the role of inflammation in CD and describe the surgical approaches for the prevention of the almost inevitable recurrence.
\end{abstract}

Keywords: Crohn's disease, Intestinal inflammatory diseases, Crohn's disease recurrence, Surgery

\section{Background}

Crohn's Disease (CD) is a chronic inflammatory intestinal disease, first described as regional ileitis by Crohn, Ginzburg and Oppenheimer in a case series presented at American Medical Association annual meeting in 1932 [1]. CD inflammation interests the whole intestine, being the most frequently affected part the distal ileum. Patients with $\mathrm{CD}$ experience periods of flares and periods of remissions during their disease course. Pathogenesis results from the interactions of environmental factors, immune system, susceptibility genes and host's microbiome changes, leading to disruption of the intestinal mucosa. The role of inflammatory cells in maintaining an active disease is well known and most of the therapies

\footnotetext{
* Correspondence: sigisica@gmail.com

'Department of Surgical Science, University Tor Vergata, Viale Oxford 81, 00133 Rome, Italy

${ }^{2}$ Torvergata Oncoscience Research Centre of Excellence, TOR, Department of Experimental Medicine, University Tor Vergata, Rome, Italy

Full list of author information is available at the end of the article
}

aim to stop the cascade of inflammatory and proinflammatory cytokines.

Treatment of $\mathrm{CD}$ is multidisciplinary: medical treatment is focused on mucosal healing and symptoms reduction; surgery maintains a key-role in treating complications such as stenosis, perforations, fistulas and abscesses. Surgical recurrence is known to afflict over $80 \%$ of the operated patients $[2,3]$. Multiple surgical strategies have been investigated to improve outcome. Introduction of laparoscopic techniques has permitted several improvements but failed in reducing recurrences; other surgical techniques are currently under evaluation in view to retard or prevent the ineluctable recurrence but the surgical cure for $\mathrm{CD}$ is yet to be discovered. This review is focused on $\mathrm{CD}$ inflammation and will discuss potential strategies to prevent recurrences, such as novel surgical approaches. 


\section{Pathogenesis and inflammation}

Crohn's disease pathogenesis is based on tissue inflammation, caused by an unrestrainable immune response against luminal bacterial antigens (Fig. 1). Immune cells like CD4 T-Cells, CD8 T-Cells, B-Cells, CD14 monocytes and natural killers, are involved in this process as they infiltrate the gut of $C D$ patients. Part of the immune-mediated susceptivity to $\mathrm{CD}$ resides in some innate mechanisms of defense form infectious diseases and the intestinal mucus secretion is part of those. It has been shown that variants of the Muc2 gene reducing mucus production are associated to $C D$ in a mouse model. Moreover, molecules that are mediating bacterial adhesion have been correlated to the disease. This is the case of FUT2, which encodes for the fucosyltransferase enzyme, responsible for the secretion of soluble forms of the $\mathrm{ABO}$ antigens. People harboring a FUT2 variants decreasing the secretion of the antigens, have an altered interaction with bacteria and are more prone to developing CD [4]. The pathogenesis is also sustained by the interaction of these cells with integrins, adhesion molecules and multiple chemokines, responsible for the production of elevated levels of inflammatory cytokines, representing the target of immune and non-immune cells and the promotion of mucosal inflammation. As such, among many adhesion molecules, some evidences on the involvement of the leucocyte MAcCAM-1, receptor for the $\alpha 4 \beta 4$ integrin, seems to play a crucial role. Together with leucocyte adhesion, the role of the extracellular matrix on their activation has been explored. Proteins like CD44 and CD26 where shown to play a role as well as metalloproteins (MMP), being MMP1 and MMP3 abundant in the granular tissue close to CD sites of inflammation, therefore responsible for leucocytes activation [5-8]. In the mucosa of CD patients, a dysregulation of various components of the immune system is invariably found. The most pronounced alteration is the hyperactivity of $\mathrm{T}$ cells with excessive production of cytokines, between which IL-12 and IFN- $\gamma$, promoting a $\mathrm{T}_{\mathrm{H}} 1$ lymphocytic phenotype, opposed to the $\mathrm{T}_{\mathrm{H}} 2$ one, correlating to ulcerative colitis. Moreover, TNF- $\alpha$ production has also been demonstrated to increase the number of CD4+ FoxP3+ $\mathrm{T}_{\mathrm{REG}}$ cells, especially in the mucosa of children affected by CD [9]. The inhibition of

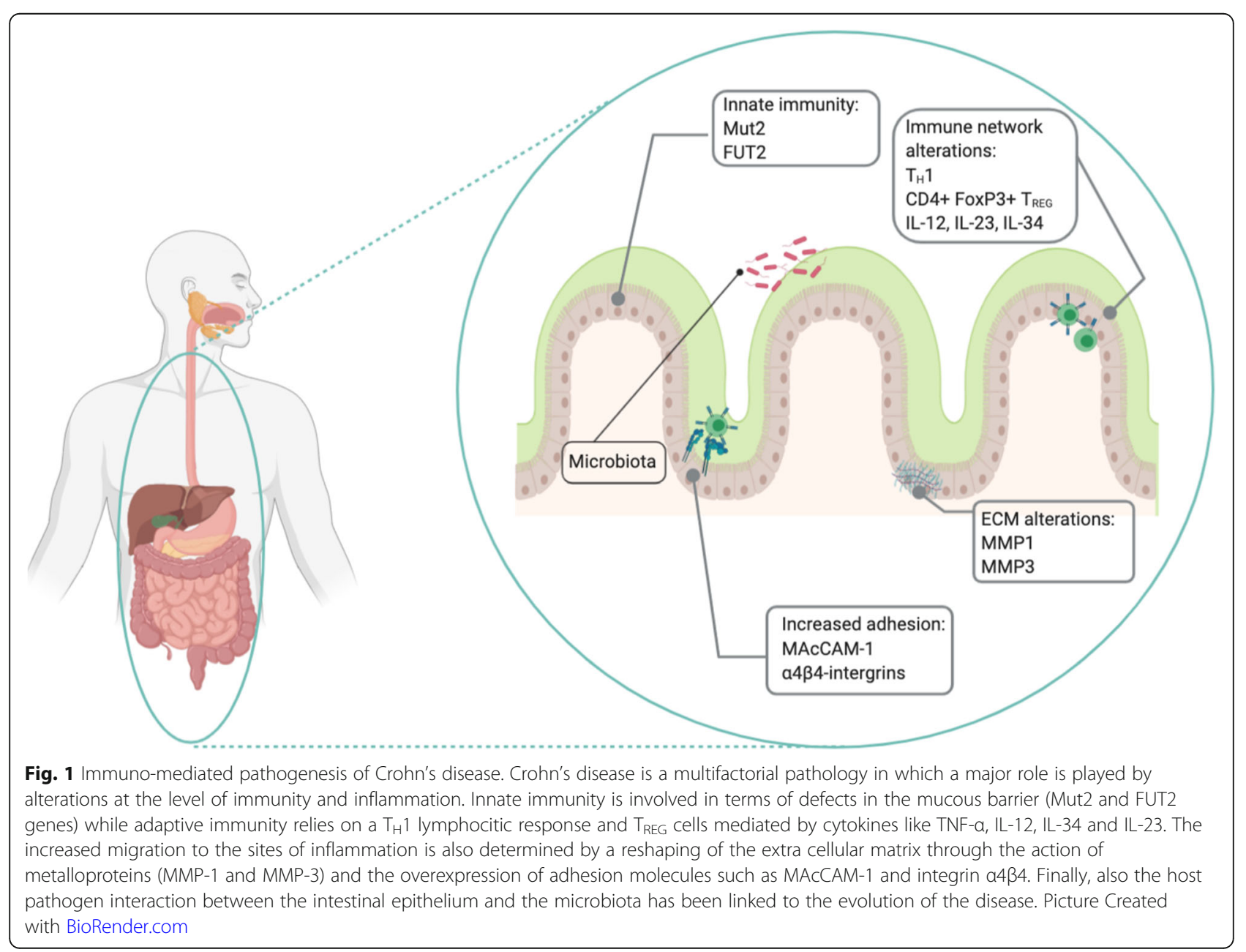




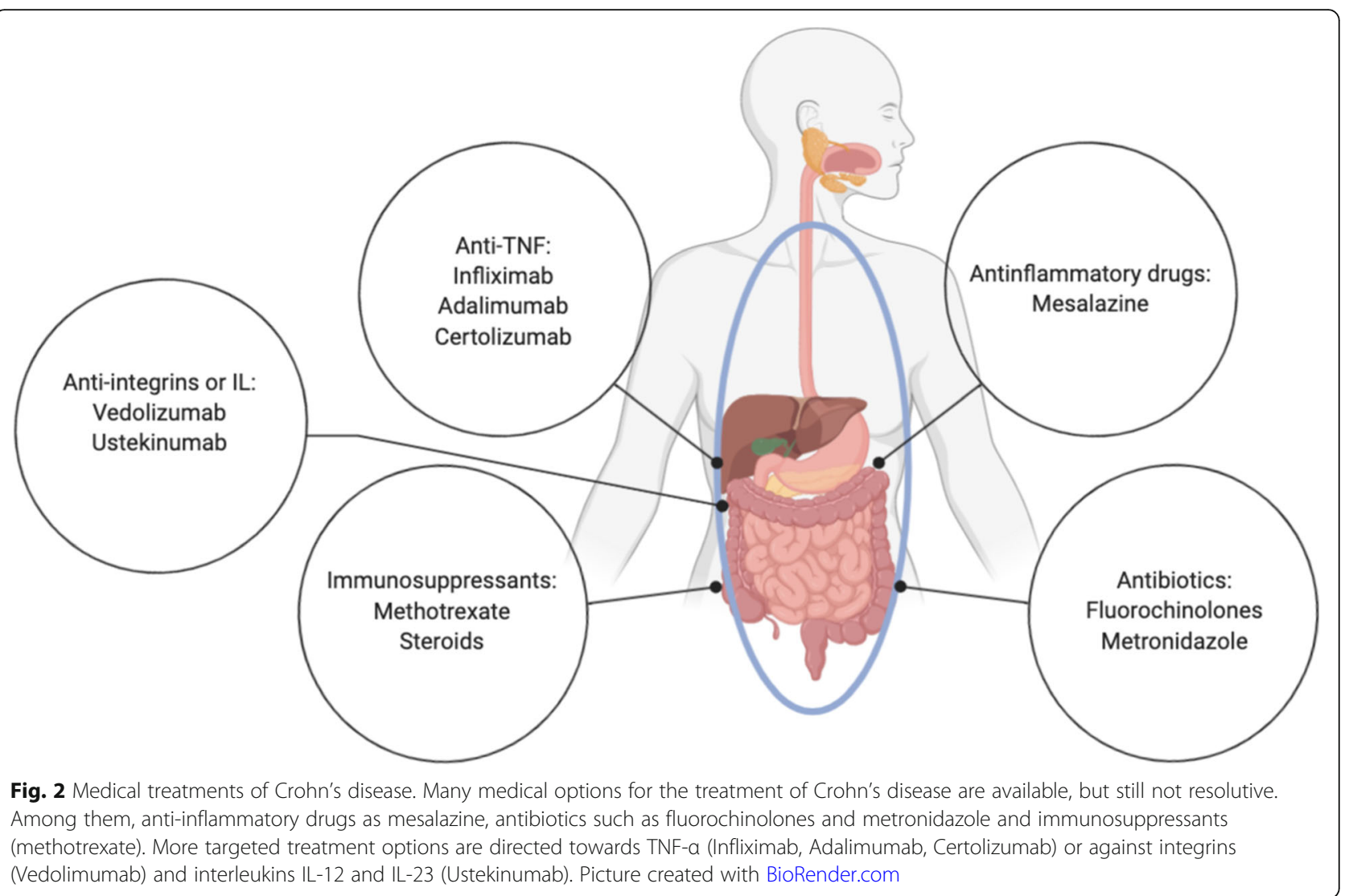

the effector cytokines, like TNF- $\alpha$, attenuates the detrimental effects in subsets of CD patients. Furthermore, the expression of the interleukins, a subgroup of cytokines implicated in the enhanced or inhibition of other cytokines in many different regulatory pathways such as maturation, growth and responsiveness of immune cells population, is to be considered anomalous in CD patients [10]. Further analysis of $\mathrm{T}$ cell subsets has revealed the presence of $T_{H} 1$ and $T_{H} 17$ cells in $C D$, whereas the cytokines considered more involved are TNF, IL12 and IL23. Apart from the cited cytokines, IL-34 has also been associated to IBD and CD in particular. IL34 expression is more pronounced in the areas of active inflammation, especially in CD, and seems to induce TNF- $\alpha$ and IL6 expression through a ERK-mediated mechanism. Moreover, IL-34 has been described as an inducer of CCL20 through the interaction with its receptor the M-CSFR1, abundantly expressed in the inflamed colonic epithelium but not in the healthy controls. On the contrary, IL-25 inversely correlates to the inflammatory state of the patients with IBD, being reduced in CD patients as opposing to healthy subject, and being reduced in the affected areas of the colon if compared to the surrounding adjacent normal tissue from the same subject. Among all the possible interleukins associated to $\mathrm{CD}$ pathogenesis, IL12 and IL-23 represent the target of still inadequate therapies because of potential side effects, such as increased risk for infection, and the blockade of specific immunological targets, capable of induction of alternative signaling or homing pathways. The latter mechanism may also partially explain the frequent lack of response to therapy with biologics such as Infliximab (Remicade@), a chimeric monoclonal antibody used to treat autoimmune diseases, that works by binding to TNF- $\alpha$ causing the reduction of IL-34 expression, implicated in monocyte and macrophage differentiation, survival and function [11-15].

Although T-Cells are the main effector lymphocytes in intestinal tissue inflammation, also humoral immune system plays a crucial role. Plasma cells differentiation indeed is promoted by CD4 T-Cells, through a mechanism that is firmly dependent on IL-2, overproduced in CD patient's gut. IL-21 converts naive B-Cells into BCells expressing granzyme-B: it possesses a cytotoxic activity on the intestinal mucosa and perpetuates the epithelial damage. These proofs indicate that an altered balance between effector and counter regulatory factors is probably involved in the sustainment of the tissuedamaging immune response in $\mathrm{CD}$ [16].

Gut microbiota also plays a recognized role in designing the inflammatory response in IBD and especially in $\mathrm{CD}$. There is growing evidences that some microbial 
gene products can influence gene expressions in the host [17-19]. The complex network arising from this assumption is referred to as the microbial-associated molecular pattern (MAMP) which is sensed by toll-like receptors on immune cells, contributing to their activation in the context of the chronic inflammation [20]. Microbiome moreover represent a source of potential pathogenic inputs that can be approached through the methods used in the omics era, such as metagenomics studies, also impacting on our knowledge on geographical variations on the clinical manifestation of the disease [21-24]. The inflammation is generally transmural and, on pathology examination, granulomas may be identified on biopsies, with a discontinuous distribution along the longitudinal axis. This inflammatory process often leads to irreversible tissue damage in the form of intestinal stenosis or fistulas, inflammatory masses or intra-abdominal abscesses. Patients can develop one or more of these disease behavior and they often tend to evolve from inflammatory to penetrating or stricturing disease [25].

\section{Medical management}

Medical management (Fig. 2) should be tailored based on various factors such as disease severity, subtype, behavior and location [26]. Moreover, it is important to consider other factors such as age at diagnosis, extension of the lesions and extra-intestinal manifestations [27]. As matter of fact, none of the drugs used in the treatment of $\mathrm{CD}$ has been demonstrated to be curative or completely safe.

Mesalazine, which belong to the 5-ASA compounds category, has been evaluated in many studies and it has never shown to definitely induce or maintain remission in CD. Its benefits are related to its safety outline [28].

Antibiotics are principally recommended to treat septic complications; like mesalazine, they do not show a real efficacy in the treatment of $\mathrm{CD}$, except in the shortterm treatment of perianal fistula in association with anti-TNF. Most frequently used agents are fluoroquinolone and metronidazole [29].

Systemic corticosteroids show a fast onset of action and are indicated to induce remission. Unfortunately, steroid dependency or steroid resistance can jeopardize their use that is often accompanied to a wide range of side effects like obesity, hypertension, glaucoma, cataracts and adrenal insufficiency [30].

Another major part is played by immunosuppressant like thiopurines and methotrexate: thiopurines are used to maintain remission in moderate $\mathrm{CD}$, usually in combination with steroids. Before starting thiopurines treatment, it is mandatory to assess TPMT (Thiopurine S-methyltransferase) activity, crucial for their metabolism [31]. Methotrexate may be considered as an option for steroid-dependent patients. Included in the side effects are hepatotoxicity and more rarely myelosuppression; they are prohibited during pregnancy because teratogenic and abortifacient [32].

Anti-TNF drugs are considered the most powerful tools to treat moderate and severe form of $\mathrm{CD}$, alone or in association with immunomodulators to obtain and maintain remission. The most frequently used anti-TNF are: Infliximab (Remicade $\odot$ ), a chimeric antibody that is administered intravenously; Adalimumab (Humira $\odot$ ), a fully humanized monoclonal antibody administered subcutaneously; Certolizumab (Cimzia $\odot$ ), a FaB antibody fragment of humanized anti-TNF molecule [33].

More recently super-selective target monoclonal antibodies have been developed, directed against a specific pattern of inflammation. In this class there are Vedolizumab (Entyvio $\odot$ ), that targets the adhesion molecular inhibiting leukocyte migration [34], and interleukininhibitors like Ustekinumab (Stelara $\odot$ ), a fully humanized monoclonal antibody targeting the p-40 subunit of IL-12 and IL-23 [35].

\section{Surgical management and $C D$ recurrence}

When $C D$ was described for the first time, therapy was exclusively surgical. Since the beginning of CD surgery experience, there was no consensus on the optimal procedure. At the Mount Sinai Hospital in New York, Dr. Berg was the surgeon who operated fourteen patients presented by Crohn. The "Berg" operation, also known as "Mount Sinai" operation, implied exclusion bypass of the ileocecal region, transecting small bowel proximal to the diseased ileum, over sewing distal ileum, and anastomosing the proximal ileal end into the mid-transverse colon [36, 37]. In fact, this was a staged management, being the second planned step the resection of the diseased bowel. Performing more and more cases, Mount Sinai surgeons noted that during the second stage of surgery, the bypassed bowel seemed to have "healed" in several cases. Starting from this observation and as patients manifested clinical improvements, they decided to omit the planned second procedure. Obviously, a great debate about this procedure and all early and late risks linked to it arose: blow out of the blind end, reactivation of $\mathrm{CD}$ in the excluded segment with abdominal pain and infections, deprivation of a large portion of the colon for water absorption. Eventually, bypass procedure was abandoned due to findings of adenocarcinoma occurring in the excluded segment $[19,38-40]$. Surgical resection of the diseased bowel emerged as the procedure of choice for most patients with $\mathrm{CD}$ of the terminal ileum or with ileo-colitis, including complicated cases [41]. In tandem, advances in perioperative care, such as nutritional improvement, anesthesia and fluid and electrolyte management, guaranteed CD surgery improvements and 
safety. At this point physician focused on the amount of resection. In fact, it was commonly accepted practice for surgeons to resect all macroscopically involved intestine with large resection margins. Consciousness of $\mathrm{CD}$ as a pan-enteric affection and, above all, the evidence of the inevitable recurrence and possible development of short bowel syndrome due to repetitive surgery, suggested the adoption of a conservative policy, avoiding wide resections [42]. For this reason, in order to avoid short bowel syndrome - in particular in those scenarios characterized by extensive jejunal-ileitis with fibrotic stenosing segments scattered along the diseased intestine - Lee from Oxford, in 198, reported another advancement in surgical management. Lee was inspired by the work of Indian surgeons on the management of tuberculous strictures: they observed that small bowel preservation could be achieved in patients with multiple tuberculous strictures by strictureplasty [43]. Lee applied strictureplasty to the short intestinal strictures of Crohn's disease and from that moment, with a great variability on techniques according to the different situations, strictureplasty assumed a fundamental role for CD surgeons $[44,45]$.

Different strictureplasty techniques have been described. Heineke-Mikulicz strictureplasty consists of a longitudinal enterotomy closed in a transverse direction and it is best applied to stricture up to $7 \mathrm{~cm}$ in length [46]. Finney strictureplasty is used for longer stenosis, up to $10-20 \mathrm{~cm}$ : after an antimesenteric longitudinal incision, the opened bowel segment is bent into a $U$ shape and posterior and anterior layers are close with continuous absorbable suture [47]. Michelassi strictureplasty is indicated for the treatment of multiple strictures, interesting up to $90 \mathrm{~cm}$ long bowel segment; in this case, a segment of diseased bowel is anastomosed to a nonaffected segment of intestine [48].

Interestingly this technique has shown to induce remission in the diseased part. The mechanism is still unknown, however there seems to be a process in $C D$ whereby obstruction is responsible for the pathogenesis of many complications [49]. This technique allows the mitigation of fecal stasis, which may play a central role in postoperative mucosal healing, modifying the microbial-mucosal interaction. Possibly, the resolution of chronic obstruction may interrupt the cascade of events causing active disease [50-52].

Another cornerstone in $\mathrm{CD}$ surgery was represented by the advent of minimally invasive surgery. Feasibility and safety of laparoscopic ileo-cecal resection has been assessed and it was found not inferior in terms of outcomes when compared to open surgery [53-55]. Nowadays, laparoscopy is largely accepted as the first line approach for $\mathrm{CD}$, in the presence of adequate expertise [56]. Laparoscopy demonstrated advantages in terms of cosmetics and postoperative recovery and assured some long-term advantages, including fewer incisional hernias, fewer adhesions and a significant impact on female fertility $[57,58]$; unfortunately, no clear differences on time to recurrence was found.

From a surgical point of view CD recurrence should be considered as an inevitable consequence.

The same factors that underline the pathogenesis of $\mathrm{CD}$ at its first stages are thought to be responsible for post-operative recurrence (POR) setting, being the result of interplay of microbial, environmental, immunological and genetic variables [59]. Within this contest, microbial flora role seems to be linked to the fecal stream, as demonstrated by Rutgeerts et al. $[60,61]$ investigating the rapid recurrence of microscopic inflammation in the mucosa of excluded ileum when newly interested by fecal content.

The term post-operative recurrence is used to define the appearance of new lesions after bowel resection. Active surveillance for an early diagnosis is considered mandatory. Rutgeerts endoscopic index is possibly the most widely used scoring system to detect recurrent lesions [62, 63]. Previous studies demonstrated that the lesions are located more often in or near the area of anastomosis, usually reproducing the same initial pattern of the disease, though it has been suggested that postresection lesions should be considered new. The presence of microscopic lesion, detected during endoscopic examinations 1 year after surgery, reinforces their role as precursors of POR. Timing of endoscopic surveillance has been discussed taking into account available evidence; recommendation is to perform endoscopic examination after 6 months from surgery or within the first year $[64,65]$. Other techniques have been investigated to assess POR [66]; in particular, there is a great interest in non-invasive techniques such as ultrasonography (US). Among several emerging US technique, Small Intestine Contrast Ultrasonography (SICUS) resulted more sensitive in detecting small bowel lesions in CD patients [67]. SICUS has been demonstrated to be comparable to ileocolonscopy, also after surgery, allowing the visualization of extra luminal lesions related to $\mathrm{CD}$ (bowel wall thickness, mesenteric and lymph nodes enlargement). Hence, in expert hands, SICUS could be considered a valid alternative for the follow-up and early diagnosis of POR after surgery in $\mathrm{CD}$ [68-71].

\section{POR: new discoveries and trends}

Other recent interesting fields of investigation focus on the role of anastomosis configuration and the mesentery function in the pathogenesis of POR.

For what concern anastomosis, a great debate was raised regard which technique should be considered optimal, in particular between the more frequent choices: side-to-side versus end-to-end configuration 
and mechanic stapled versus hand sewn. In $2014 \mathrm{He}$ [72] carried out a meta-analysis to compare stapled sideto-side anastomosis (SSSA) and hand sewn end-to-end anastomosis (HEEA) in terms of postoperative early and late complications and POR after ileo-colic resection for $\mathrm{CD}$. The conclusion was that SSSA should be preferred because of its larger luminal diameter, thus showing lower overall incidence of complications including anastomotic leak, lower recurrence and re-operation for recurrence. In 2018, Feng [73] carried out a similar meta-analysis, looking specifically at the orientation of the anastomosis. Feng concluded that SSSA isoperistaltic is probably the optimal anastomosis because it can significantly reduce incidence of overall postoperative complications and clinical POR. The underlying idea is that, with its wide lumen configuration, SSSA isoperistaltic reduces recurrence by preventing early stenosis, colonic reflux and secondary ischemia. In 2018 Gajendran [74] published his series, supporting the superiority of HEEA when compared to anti-peristaltic SSSA. He also looked into the impact on quality of life and inflammatory activity. Gajendran developed an experimental animal model to provide a mechanistic explanation for his clinical findings, showing that antiperistaltic orientation alters anatomy and physiology, creating an anti-peristaltic reservoir, which causes dysmotility and alteration in contractility. In particular, the animal model showed that this is due to the perpendicular surgical trans-section of the intestinal circular muscle layers: disruption of motility seems to lead to significant structural and functional changes with local stasis of enteric contents and local distension at the anastomotic site. Gajendran concluded that, according to his data, the restoration of physiologic intestinal function with surgical reconstruction of the bowel as an intact tube could contribute to a better outcome in CD patients. In the same year, Aaltonen's group [75] published its series regarding risk factors for anastomotic recurrence. Aaltonen's et al. proposed a technical variant HEEA, adding an opening of the small bowel's anti-mesenteric border to ensure enough wide bowel lumen, describing this modified technique as a safe choice for ileo-colonic resection. Current guidelines from the American Society of Colon and Rectal Surgeons [76], states that anastomosis can be constructed as deemed most appropriate by the surgeon. ECCO guidelines [53] more recently, seems to favor SSSA, taking into account He and Feng's meta-analysis $[72,73]$ and stressing the concept that a wider anastomosis will have a lower rate of clinical and surgical recurrence.

Within this context, Toru Kono developed a new anastomotic technique. The first Kono-s anastomosis' (KSA) work was published in 2011 [77]. KSA is an antimesenteric functional end-to-end hand sewn anastomosis, configured so that the mesentery side is located in the center of the stump. Both stumps are sutured to create a "supporting column" to maintain the diameter and dimension of the anastomosis, preventing distortion and stenosis associated with recurrent disease at the anastomotic side, especially on the mesenteric side, which represents a locus minoris resistentiae and so a typical recurrence location. In 2012 Fichera [78] highlighted KSA innovations: the theoretical advantages of the complete exclusion of the mesentery, the initial site of CD POR, with a true antimesenteric anastomosis; lower susceptibility to mechanical distortions due to the stability provided by the "supporting column"; better preservation of blood supply and innervation, achieved by dividing the mesentery close to the bowel. Moreover, in 2015, Katsuno published his series confirming safety, feasibility and good results and highlighted the easier endoscopic access to the KSA [79]. Results from the first International Multicenter Study [80], leaded by Kono himself, were available in 2015 and the authors suggested resection and KSA for CD patients who are not candidates for anti-TNF therapy due to adverse effects, loss of efficacy or financial reasons. In 2018, Seyfried [81] and Shimada [82] published two more series and in 2020, during the ECCO Congress in Vienna, Luglio presented the results of "The SuPREMe-CD Study" [83], the first randomized clinical trial comparing KSA and SSSA in terms of endoscopic and surgical recurrence, confirming a reduction in POR when KSA is performed. Multicenter trials are still needed to further confirm these preliminary results. Indeed, the interest on anastomotic configuration is still open and recently Celentano developed a model for a V-modified side-to-side, antimesenteric, iso-peristaltic anastomosis in which a strictureplasty is added to the inlet and the outlet of the anastomosis. Celentano's configuration target is the widening of the lumen of the bowel in these two critical areas, with the aim of minimizing the risk of clinical and surgical anastomotic recurrence; this is just a model ex vivo but representative of the wide interest in this field [84].

The role of the mesentery could be considered the other trending topic of the last decade. The underlying idea is that the mesentery plays a prominent role in CD pathogenesis and in recurrences. Mesentery is seen as an independent organ, interposed between the intestine and the body. From its privileged location, mesentery is responsible for the conduction of local intestinal and systemic response: it is the reservoir of various cell types, in particular inflammatory ones, contained in lymph nodes and related mediators [85]. Moreover, CD mesentery shows the pathognomonic phenomenon known as fat wrapping or creeping fat [86], consisting of a peculiar form of adipose tissue hypertrophy. Creeping fat is characterized by small adipocytes, increased in number with a specific gene expression profile, accompanied to 
immune cell infiltration, comprising regulatory M2 macrophages and T-cells [87]. Guedj et al. [88], thanks to in vitro experiments on resection specimens of ileum from patients operated for $\mathrm{CD}$, proposed a mechanism in which mesenteric adipocyte, through their production of key chemokines in response to inflammatory/bacterial stimuli, orchestrate an immune response in CD-affected mesentery.

Between 2015 and 2016, Li published two different papers regarding this topic. In the first one [89] he focused on the contribution of the mesenteric adipose tissue, measuring the fat visceral area - assimilated to the creeping fat phenomenon - in CT scan performed before surgery; in this retrospective study also subcutaneous fat area and mesenteric fat index, defined as the ratio of visceral and subcutaneous fat were considered. As result, high fat visceral area was found to be and independent predictor of early clinical recurrence of CD POR.

In the second paper [89], Li highlighted the contribution of mesenteric nerves, vessels, lymphatics and fat mass, concluding that all these structures play a crucial role in $\mathrm{CD}$ pathogenesis and disease progression. $\mathrm{He}$ provided the basis for the Copernican revolution in CD pathogenesis, querying the current dominant theory in $\mathrm{CD}$, based on the unidirectional, "outside-in" axis of dysbiosis, innate immunity-adaptive immunity-mesenterybody system. Emerging clinical evidence strongly suggest that the axis is bidirectional, involving also all the cited mesenteric structures, and not only endoluminal agents as already cited in the pathogenesis section.

Coffey and Rivera $[90,91]$ gave other further hints to remove the veil of Maya on the pathogenesis and the mesenteric role. They started from the assumption that topographic distribution of Crohn's disease along the intestinal tract may have a bodily mesenteric basis in terms of tissue volume and thickness. As a proof, they noted that the largest mesenteric region is the ileocolic region, which happens to be also the commonest localization of CD.

In 2018 Mao [92] gave more insights on how creeping fat influences stricture formation in CD; he took into account mechanisms involved in the microenvironment at interfaces of different tissue compartments, such as creeping fat, considered as an extension of mesenteric fat beginning at the intestinal hilum, and the intestine muscularis mucosa itself. As already emphasized, in creeping fat immune and nonimmune cell types are represented and increased in number, producing mediators responsible for intestinal stricture formation. Among these cells, fatmesenchymal cells seem to play a pivotal role because their interactions appear to be important in tissue remodeling in multiple organs, including the intestine. Hence, creeping fat abandons the old role of innocent bystander and is acknowledged as an active participant in inflammation and immunity. Mao hypothesized also that stricture formation incidence has remained unchanged because no target-therapy is available and so cells involved in this process should represent a pharmacological target.

Therefore, the awareness of the central mesentery's role provides a Copernican revolution also in terms of clinical target. In fact, from this point of view, mesentery could be considered as an anatomical sacrarium: there are no valid pharmacotherapeutic modalities designed specifically to manipulate it. At present, the only means of targeting the mesentery are surgical, so there is the need for development of new strategies in this field.

Even though conservative approach to intestinal resection in CD could be considered an established dogma, in the light of the recent discovered role of mesentery, the attitude is changing. Up to the present, mesentery resection has not become standard practice. This is mainly due to technical concerns regarding risk of bleeding when manipulating tissues with significant inflammation, disease-related perforation, fistula formation, adhesions, and thickened mesentery, potentially leading to complications like hemorrhage, hematomas and other injuries. Overcoming these issues and starting from the previous considerations, Coffey et al. [93] published a series on the inclusion of mesentery in ileocolic resection for $\mathrm{CD}$. Clinical findings were coherent with formulated theories: inclusion of the mesentery as part of intestinal resection is associated with reduced POR, that means improved clinical outcomes, and advanced mesenteric disease resulted to be a predictor of increased risk of POR. Moreover De Groof et al. presented a series on proctectomy in $\mathrm{CD}$, demonstrated that perineal complications were more frequent after close rectal dissection than after total mesorectal excision [94]. These results suggested a pathogenic role for the mesorectal tissue in $\mathrm{CD}$. In the footsteps of these assumptions, an international, multicenter, randomized controlled trial [95] is ongoing about the mesenteric excision surgery versus conservative limited resection in $\mathrm{CD}$. Moreover, our group is running the PANACEA study (Pathophysiological, Nodal-based Approach for Crohn's disease Excision), a pilot yet unpublished study, based on the belief that the majority of T-cells - especially memory T-cells - lies in lymph nodes [96-99]. Our hypothesis is that mesenteric resection, including lymph nodes, should free the organism from a great number of cells involved in intestinal inflammation. Results from this study altogether with the others, will contribute to understand which of the proposed approach will be valid in reducing POR.

\section{Conclusions}

Crohn's disease has been seen, in the last two decades, as a multifactorial inflammatory disease. Much is known in terms of its pathogenesis from a molecular point of view from the involvement of the mucosal mucinous 
barrier and the role played by variants of the Mut2 or the FUT2 genes, which alters the barrier interaction with both pathogens and harmful substances, to the complex mechanisms involving aberrant expression of adhesion molecules. The leucocytic MAcCAM-1 is a mediator of integrin dependent adhesion, which is part of the mechanism leading to migration of leucocytes in CD inflamed region. On the other front, the migration of inflammatory cells is also mediated by the alteration of the extracellular matrix, often mediated by MMP proteins, being MMP-1 and MMp-3 the most abundant in this clinical context.

The complex milieu that is created by the interaction of the inflammatory cells with the intestinal epithelium is sustained by a complex network of cytokines and chemokines, which direct $\mathrm{T}$ lymphocytes towards a $\mathrm{T}_{\mathrm{H}} 1$ response, mediated by the expression of the FoxP3 transcription factor in the $\mathrm{T}_{\mathrm{REG}}$ population. Among the cytokines involved in CD pathogenesis, IL-34 and IL-25 seem to play opposing roles, the first increased in the injured tissue, the second one diminished. Other cytokines such as IL-12 and IL-23 have been demonstrated paying a key role in the inflammatory response and are some of the few current medical therapeutic targets for CD. Anyhow, considering that a consistent part of CD therapeutic approaches remains surgical. We reviewed emerging surgical approaches considered useful in preventing POR in $C D$ patients. The mesentery seems to play a pivotal role in maintaining inflammation in intestinal CD. Many studies already confirmed mesenterybased surgery as a valid approach, with improved outcomes; ongoing randomized controlled trial should help to settle the question.

\section{Acknowledgements}

Not applicable.

\begin{abstract}
Authors' contributions
Lorenzo Petagna, Amedeo Antonelli, Carlo Ganini and Giuseppe Sica, wrote the manuscript and approved the final version. Marzia Franceschilli, Andrea Guida, Sara Ingallinella, Bruno Sensi, Leandro Siragusa, Michela Campanelli, Vittoria Bellato, Andrea Divizia, did the systematic bibliography research and contributed equally in retrieving data and analysing results. They all approved the final manuscript. Cesare Efrati and Fabrizio Montagnese, gave their clinical gastroenterology expertise, adding valuable material to the manuscript. They both critically review the whole text and approved the final version of the manuscript.
\end{abstract}

\section{Funding}

The European Society Degenerative Disease supported the publication of this review.

Availability of data and materials

Not applicable.

Ethics approval and consent to participate

Not applicable.

Consent for publication

Not applicable.

\section{Competing interests}

The Authors declare that they have no competing interests.

\section{Author details}

'Department of Surgical Science, University Tor Vergata, Viale Oxford 81, 00133 Rome, Italy. ${ }^{2}$ Torvergata Oncoscience Research Centre of Excellence, TOR, Department of Experimental Medicine, University Tor Vergata, Rome, Italy. ${ }^{3}$ Ospedale Israelitico, Department of Gastroenterology, Rome, Italy.

${ }^{4}$ Nuovo Ospedale dei Castelli, Endoscopy Unit, Rome, Italy.

Received: 27 October 2020 Accepted: 30 October 2020

Published online: 07 November 2020

\section{References}

1. Crohn BB. Regional ileitis. JAMA. 1932;99(16):1323.

2. Assche GV, Rutgeerts P. Medical management of postoperative recurrence in Crohn's disease. Gastroenterol Clin North Am. 2004;33(2):347-60.

3. Rutgeerts P, Van Assche G, Vermeire S, D'Haens G, Baert F, Noman M, et al. Ornidazole for prophylaxis of postoperative Crohn's disease recurrence: a randomized, double-blind, placebo-controlled trial. Gastroenterology. 2005; 128(4):856-61.

4. Wallace KL. Immunopathology of inflammatory bowel disease. World J Gastroenterol. 2014;20(1):6.

5. Papadakis KA. Chemokines in inflammatory bowel disease. Curr Allergy Asthma Rep. 2004;4(1):83-9.

6. Fiocchi C. Intestinal inflammation: a complex interplay of immune and nonimmune cell interactions. Am J Physiol. 1997;273(4):G769-75.

7. De Simone V, Ronchetti G, Franzè E, Colantoni A, Ortenzi A, Fantini MC, et al. Interleukin-21 sustains inflammatory signals that contribute to sporadic colon tumorigenesis. Oncotarget. 2015;6(12):9908-23.

8. Sileri P, Sica G, Gentileschi P, Venza M, Manzelli A, Palmieri G, et al. Ischemic preconditioning protects intestine from prolonged ischemia. Transplant Proc. 2004;36(2):283-5.

9. de Souza HSP, Fiocchi C. Immunopathogenesis of IBD: current state of the art. Nat Rev Gastroenterol Hepatol. 2016;13(1):13-27.

10. Sarra M, Cupi ML, Monteleone I, Franzè E, Ronchetti G, Di Sabatino A, et al. IL-15 positively regulates IL-21 production in celiac disease mucosa. Mucosal Immunol. 2013;6(2):244-55.

11. Franzè E, Dinallo V, Rizzo A, Di Giovangiulio M, Bevivino G, Stolfi C, et al. Interleukin-34 sustains pro-tumorigenic signals in colon cancer tissue. Oncotarget. 2018;9(3):3432-45.

12. Pellino G, Keller DS, Sampietro GM, Angriman I, Carvello M, Celentano V, et al. Inflammatory bowel disease position statement of the Italian Society of Colorectal Surgery (SICCR): Crohn's disease. Tech Coloproctol. 2020;24(5): 421-48. https://doi.org/10.1007/s10151-020-02183-z Epub 2020 Mar 14. PMID: 32172396.

13. Fina D, Franzè E, Rovedatti L, Corazza GR, Biancone L, Sileri PP, et al. Interleukin-25 production is differently regulated by TNF- $a$ and TGF- $\beta 1$ in the human gut. Mucosal Immunol. 2011;4(2):239-44.

14. Marafini I, Monteleone I, Di Fusco D, Cupi ML, Paoluzi OA, Colantoni A, et al. TNF-alpha producing innate lymphoid cells (ILCS) are increased in active celiac disease and contribute to promote intestinal atrophy in mice. PLoS One. 2015;10(5):e0126291.

15. Neurath MF. Targeting immune cell circuits and trafficking in inflammatory bowel disease. Nat Immunol. 2019;20(8):970-9.

16. Cupi ML, Sarra M, Marafini I, Monteleone I, Franzè E, Ortenzi A, et al. Plasma cells in the mucosa of patients with inflammatory bowel disease produce granzyme B and possess cytotoxic activities. J Immunol. 2014;192(12):6083-91.

17. Caputo A, Fournier P-E, Raoult D. Genome and pan-genome analysis to classify emerging bacteria. Biol Direct. 2019;14(1):5.

18. Walker AR, Datta S. Identification of city specific important bacterial signature for the MetaSUB CAMDA challenge microbiome data. Biol Direct. 2019;14(1):11.

19. Han Y, Ye X, Wang C, Liu Y, Zhang S, Feng W, et al. Integration of molecular features with clinical information for predicting outcomes for neuroblastoma patients. Biol Direct. 2019;14(1):16.

20. Walker AR, Grimes TL, Datta S, Datta S. Unraveling bacterial fingerprints of city subways from microbiome 16S gene profiles. Biol Direct. 2018;13(1):10.

21. Casimiro-Soriguer CS, Loucera C, Perez Florido J, López-López D, Dopazo J. Antibiotic resistance and metabolic profiles as functional biomarkers that 
accurately predict the geographic origin of city metagenomics samples. Biol Direct. 2019;14(1):15.

22. Ryan FJ. Application of machine learning techniques for creating urban microbial fingerprints. Biol Direct. 2019;14(1):13.

23. Gerner SM, Rattei T, Graf AB. Assessment of urban microbiome assemblies with the help of targeted in silico gold standards. Biol Direct. 2018;13(1):22

24. Osmanovic D, Kessler DA, Rabin Y, Soen Y. Darwinian selection of host and bacteria supports emergence of Lamarckian-like adaptation of the system as a whole. Biol Direct. 2018;13(1):24

25. Rodriguez T, Karpin J, Traboulsi C, Rai V, Rubin D. P314 C-reactive protein is associated with depression and anxiety in patients with inflammatory bowel disease. J Crohns Colitis. 2020;14(Supplement_1):S311-S.

26. Torres J, Bonovas S, Doherty G, Kucharzik T, Gisbert JP, Raine T, et al. ECCO guidelines on therapeutics in Crohn's disease: medical treatment. J Crohns Colitis. 2020;14(1):4-22

27. D'Ugo S, Romano F, Sibio S, Bagaglini G, Sensi B, Biancone L, et al. Impact of surgery on quality of life in Crohn's disease: short- and mid-term followup. Updates Surg. 2020;72(3):773-80.

28. Moja L, Danese S, Fiorino G, Del Giovane C, Bonovas S. Systematic review with network meta-analysis: comparative efficacy and safety of budesonide and mesalazine (mesalamine) for Crohn's disease. Aliment Pharmacol Ther. 2015;41(11):1055-65.

29. Khan KJ, Ullman TA, Ford AC, Abreu MT, Abadir A, Marshall JK, et al. Antibiotic therapy in inflammatory bowel disease: a systematic review and meta-analysis. Am J Gastroenterol. 2011;106(4):661-73.

30. Coward S, Kuenzig ME, Hazlewood G, Clement F, McBrien K, Holmes R, et al. Comparative effectiveness of Mesalamine, sulfasalazine, corticosteroids, and budesonide for the induction of remission in Crohn's disease. Inflamm Bowel Dis. 2017;23(3):461-72

31. Bermejo F, Aguas M, Chaparro M, Domènech E, Echarri A, García-Planella E, et al. Recomendaciones del Grupo Español de Trabajo en Enfermedad de Crohn y colitis Ulcerosa (GETECCU) sobre el uso de tiopurinas en la enfermedad inflamatoria intestinal. Gastroenterol Hepatol. 2018;41(3):205-21.

32. Chande N, Abdelgadir I, Gregor J. The safety and tolerability of methotrexate for treating patients with Crohn's disease. J Clin Gastroenterol. 2011;45(7):599-601.

33. Stidham RW, Lee TCH, Higgins PDR, Deshpande AR, Sussman DA, Singal AG, et al. Systematic review with network meta-analysis: the efficacy of anti-TNF agents for the treatment of Crohn's disease. Aliment Pharmacol Ther. 2014; 39(12):1349-62.

34. Argollo M, Fiorino G, Peyrin-Biroulet $L$, Danese $S$. Vedolizumab for the treatment of Crohn's disease. Expert Rev Clin Immunol. 2018;14(3):179-89.

35. Armuzzi A, Ardizzone S, Biancone L, Castiglione F, Danese S, Gionchetti P, et al. Ustekinumab in the management of Crohn's disease: expert opinion. Dig Liver Dis. 2018;50(7):653-60.

36. Fazio WW, Aufses AH. Evolution of surgery for Crohn's disease. Dis Colon Rectum. 1999:42(8):979-88.

37. Garlock JH, Crohn BB, Klein SH, Yarnis H. An appraisal of the long-term results of surgical treatment of regional ileitis. Gastroenterology. 1951;19(3): 414-23.

38. Lightdale CJ, Sternberg SS, Posner G, Sherlock P. Carcinoma complicating Crohn's disease. Am J Med. 1975;59(2):262-8.

39. Greenstein AJ, Sachar D, Pucillo A, Kreel I, Geller S, Janowitz HD, et al. Cancer in Crohn's disease after diversionary surgery. Am J Surg. 1978;135(1): 86-90.

40. Francescatto $M$, Chierici M, Rezvan Dezfooli S, Zandonà A, Jurman G, Furlanello C. Multi-omics integration for neuroblastoma clinical endpoint prediction. Biol Direct. 2018;13(1):5.

41. Fazio WW, Marchetti F, Church JM, Goldblum JR, Lavery IC, Hull TL, et al. Effect of resection margins on the recurrence of Crohn's disease in the small bowel. Ann Surg. 1996;224(4):563-73.

42. Fazio WW, Marchetti F. Recurrent Crohn's disease and resection margins: bigger is not better. Adv Surg. 1999;32:135-68

43. Katariya RN, Sood S, Rao PG, Rao PLNG. Stricture-plasty for tubercular strictures of the gastro-intestinal tract. Br J Surg. 1977;64(7):496-8.

44. Lee EC, Papaioannou N. Minimal surgery for chronic obstruction in patients with extensive or universal Crohn's disease. Ann R Coll Surg Engl. 1982;64(4): 229-33.

45. Pellino G, Keller DS, Sampietro GM, Carvello M, Celentano V, Coco C, et al. Inflammatory bowel disease position statement of the Italian Society of Colorectal Surgery (SICCR): ulcerative colitis. Tech Coloproctol. 2020;24(5):
397-419. https://doi.org/10.1007/s10151-020-02175-z Epub 2020 Mar 2. PMID: 32124113

46. Ambe R, Campbell L, Cagir B. A comprehensive review of Strictureplasty techniques in Crohn's disease: types, indications, comparisons, and safety. J Gastrointest Surg. 2012;16(1):209-17.

47. Yamamoto T, Mylonakis E, Keighley MRB. Two surgical procedures for strictures at Finney Strictureplasty for small bowel Crohn's disease. Dig Surg. 2000;17(5):451-3.

48. Maggiori L, Michelassi F. How I do it: side-to-side Isoperistaltic Strictureplasty for extensive Crohn's disease. J Gastrointest Surg. 2012;16(10):1976-80.

49. Yamamoto T, Umegae S, Kitagawa T, Matsumoto K. Postoperative change of mucosal inflammation at Strictureplasty segment in Crohn's disease: cytokine production and endoscopic and histologic findings. Dis Colon Rectum. 2005;48(4):749-57.

50. Michelassi F, Hurst RD, Melis M, Rubin M, Cohen R, Gasparitis A, et al. Sideto-side Isoperistaltic Strictureplasty in extensive Crohn's disease. Ann Surg. 2000;232(3):401-8

51. de Buck van Overstraeten A, Vermeire S, Vanbeckevoort D, Rimola J, Ferrante $M$, Van Assche $G$, et al. Modified side-to-side Isoperistaltic Strictureplasty over the lleocaecal valve: an alternative to lleocaecal resection in extensive terminal Ileal Crohn's disease. J Crohns Colitis. 2016; 10(4):437-42.

52. Mege D, Michelassi F. Michelassi II Strictureplasty for Crohn's disease. Ann Surg. 2020;271(1):e1-2

53. Sica GS, Campanelli M, Bellato V, Monteleone G. Gastrointestinal cancer surgery and enhanced recovery after surgery (ERAS) during COVID-19 outbreak. Langenbecks Arch Surg. 2020;405(3):357-8. https://doi.org/10. 1007/s00423-020-01885-0 Epub 2020 May 11. PMID: 32390097.

54. Sica GS, Di Carlo S, D'Ugo S, Arcudi C, Siragusa L, Fazzolari L, et al. Minimal open access lleocolic resection in complicated Crohn's disease of the terminal ileum. Gastroenterol Res Pract. 2020;2020:1-6.

55. Sica GS. Comparative study of laparoscopic vs open gastrectomy in gastric cancer management. World J Gastroenterol. 2011;17(41):4602.

56. Pellino G, Keller DS, Sampietro GM, Annese V, Carvello M, Celentano V, et al. Inflammatory bowel disease (IBD) position statement of the Italian Society of Colorectal Surgery (SICCR): general principles of IBD management. Tech Coloproctol. 2020;24(2):105-26.

57. Sica GS. Surgery for inflammatory bowel disease in the era of laparoscopy. World J Gastroenterol. 2013;19(16):2445

58. Sica GS, laculli E, Benavoli D, Biancone L, Calabrese E, Onali S, et al. Laparoscopic versus open lleo-colonic resection in Crohn's disease: shortand long-term results from a prospective longitudinal study. J Gastrointest Surg. 2008;12(6):1094-102.

59. Ahmed T, Rieder F, Fiocchi C, Achkar JP. Pathogenesis of postoperative recurrence in Crohn's disease. Gut. 2011:60(4):553-62.

60. Rutgeerts $P$, Peeters $M$, Hiele M, Vantrappen $G$, Pennincx F, Aerts $R$, et al. Effect of faecal stream diversion on recurrence of Crohn's disease in the neoterminal ileum. Lancet. 1991;338(8770):771-4.

61. D'Haens GR, Geboes K, Peeters M, Baert F, Penninckx F, Rutgeerts P. Early lesions of recurrent Crohn's disease caused by infusion of intestinal contents in excluded ileum. Gastroenterology. 1998;114(2):262-7.

62. Rutgeerts P, Geboes K, Vantrappen G, Beyls J, Kerremans R, Hiele M. Predictability of the postoperative course of Crohn's disease. Gastroenterology. 1990;99(4):956-63.

63. Divizia A, Sensi B, Sica GS. Ambulatory management of perianal Crohn's disease during the COVID-19 pandemic. Colorectal Dis. 2020;22(6):645-6. https://doi.org/10.1111/codi.15104 Epub 2020 May 18.PMID: 32348620.

64. Orlando A, Mocciaro F, Renna S, Scimeca D, Rispo A, Lia Scribano M, et al. Early post-operative endoscopic recurrence in Crohn's disease patients: data from an Italian group for the study of inflammatory bowel disease (IG-IBD) study on a large prospective multicenter cohort. J Crohns Colitis. 2014;8(10): 1217-21.

65. Domènech E, López-Sanromán $A$, Nos $P$, Vera $M$, Chaparro M, Esteve $M$, et al. Recomendaciones del Grupo Español de Trabajo en Enfermedad de Crohn y colitis Ulcerosa (GETECCU) sobre la monitorización, prevención y tratamiento de la recurrencia posquirúrgica en la enfermedad de Crohn. Gastroenterol Hepatol. 2017;40(7):472-83.

66. laculli E, Agostini M, Biancone L, Fiorani C, Di Vizia A, Montagnese F, et al. Creactive protein levels in the perioperative period as a predictive marker of endoscopic recurrence after ileo-colonic resection for Crohn's disease Cell Death Dis. 2016;2(1):16032. 
67. Rispo A, Imperatore N, Testa A, Nardone OM, Luglio G, Caporaso N, et al Diagnostic accuracy of ultrasonography in the detection of postsurgical recurrence in Crohn's disease: a systematic review with meta-analysis. Inflamm Bowel Dis. 2018;24(5):977-88.

68. Biancone L, Onali S, Calabrese E, Petruzziello C, Zorzi F, Condino G, et al. Non-invasive techniques for assessing postoperative recurrence in Crohn's disease. Dig Liver Dis. 2008;40(Suppl 2):S265-70.

69. Onali S, Calabrese E, Petruzziello C, Lolli E, Ascolani M, Ruffa A, et al. Postoperative recurrence of Crohn's disease: a prospective study at 5 years. Dig Liver Dis. 2016;48(5):489-94.

70. Onali S, Calabrese E, Petruzziello C, Zorzi F, Sica GS, Lolli E, et al. Endoscopic vs ultrasonographic findings related to Crohn's disease recurrence: a prospective longitudinal study at 3 years. J Crohns Colitis. 2010;4(3):319-28.

71. Rossi P, Sileri P, Gentileschi P, Sica GS, Forlini A, Stolfi VM, et al. Percutaneous liver biopsy using an ultrasound-guided subcostal route. Dig Dis Sci. 2001;46(1):128-32.

72. He X, Chen Z, Huang J, Lian L, Rouniyar S, Wu X, et al. Stapled side-to-side anastomosis might be better than Handsewn end-to-end anastomosis in \|leocolic resection for Crohn's disease: a meta-analysis. Dig Dis Sci. 2014; 59(7):1544-51

73. J-s F, J-y L, Yang Z, Chen X-Y, Mo J-J, Li S-H. Stapled side-to-side anastomosis might be benefit in intestinal resection for Crohn's disease. Medicine. 2018;97(15):e0315-e.

74. Gajendran M, Bauer AJ, Buchholz BM, Watson AR, Koutroubakis IE, Hashash $J G$, et al. lleocecal anastomosis type significantly influences long-term functional status, quality of life, and healthcare utilization in postoperative Crohn's disease patients independent of inflammation recurrence. Am J Gastroenterol. 2018;113(4):576-83.

75. Aaltonen G, Keränen I, Carpelan-Holmström M, Lepistö A. Risk factors for anastomotic recurrence after primary ileocaecal resection in Crohn's disease. Eur J Gastroenterol Hepatol. 2018;30(10):1143-7.

76. Strong S, Steele SR, Boutrous M, Bordineau L, Chun J, Stewart DB, et al. Clinical practice guideline for the surgical Management of Crohn's disease. Dis Colon Rectum. 2015:58(11):1021-36.

77. Kono T, Ashida T, Ebisawa Y, Chisato N, Okamoto K, Katsuno H, et al. A new Antimesenteric functional end-to-end Handsewn anastomosis: surgical prevention of anastomotic recurrence in Crohn's disease. Dis Colon Rectum. 2011:54(5):586-92.

78. Fichera A, Zoccali M, Kono T. Antimesenteric functional end-to-end Handsewn (Kono-S) anastomosis. J Gastrointest Surg. 2012;16(7):1412-6.

79. Katsuno H, Maeda K, Hanai T, Masumori K, Koide Y, Kono T. Novel Antimesenteric functional end-to-end Handsewn (Kono-S) anastomoses for Crohn's disease: a report of surgical procedure and short-term outcomes. Dig Surg. 2015:32(1):39-44.

80. Kono T, Fichera A, Maeda K, Sakai Y, Ohge H, Krane M, et al. Kono-S anastomosis for surgical prophylaxis of anastomotic recurrence in Crohn's disease: an international multicenter study. J Gastrointest Surg. 2016;20(4): 783-90

81. Seyfried S, Post S, Kienle P, Galata CL. Die Kono-S-anastomose in der Chirurgie des Morbus Crohn. Chirurg. 2019;90(2):131-6.

82. Shimada N, Ohge H, Kono T, Sugitani A, Yano R, Watadani Y, et al. Surgical recurrence at anastomotic site after bowel resection in Crohn's disease: comparison of Kono-S and end-to-end anastomosis. J Gastrointest Surg. 2019;23(2):312-9.

83. Luglio G, Rispo A, Imperatore N, Giglio MC, Amendola A, Tropeano FP, et al. Surgical prevention of anastomotic recurrence by excluding mesentery in Crohn's disease: the SuPREMe-CD study - a randomized clinical trial. Ann Surg. 2020;272(2):210-7.

84. Celentano V, Luvisetto F, Toh S. Ex vivo model for a new bilateral antimesenteric $\mathrm{V}$-modified side-to-side isoperistaltic anastomosis to prevent recurrence in ileocolic Crohn's disease. Ann Royal College Surgeons England. 2019;101(5):313-7.

85. Kredel L, Batra A, Siegmund B. Role of fat and adipokines in intestinal inflammation. Curr Opin Gastroenterol. 2014;30(6):559-65.

86. Sheehan AL, Warren BF, Gear MWL, Shepherd NA. Fat-wrapping in Crohn's disease: pathological basis and relevance to surgical practice. Br J Surg. 1992;79(9):955-8.

87. Kredel LI, Batra A, Stroh T, Kühl AA, Zeitz M, Erben U, et al. Adipokines from local fat cells shape the macrophage compartment of the creeping fat in Crohn's disease. Gut. 2013:62(6):852-62.
88. Guedj K, Abitbol Y, Cazals-Hatem D, Morvan M, Maggiori L, Panis Y, et a. Adipocytes orchestrate the formation of tertiary lymphoid organs in the creeping fat of Crohn's disease affected mesentery. J Autoimmun. 2019;103: 102281

89. Li Y, Zhu W, Gong J, Zhang W, Gu L, Guo Z, et al. Visceral fat area is associated with a high risk for early postoperative recurrence in Crohn's disease. Colorectal Dis. 2015;17(3):225-34.

90. Coffey JC, O'Leary DP, Kiernan MG, Faul P. The mesentery in Crohn's disease Curr Opin Gastroenterol. 2016:32(4):267-73.

91. Rivera ED, Coffey JC, Walsh D, Ehrenpreis ED. The mesentery, systemic inflammation, and Crohn's disease. Inflamm Bowel Dis. 2019:25(2):226-34.

92. Mao R, Kurada S, Gordon IO, Baker ME, Gandhi N, McDonald C, et al. The mesenteric fat and intestinal muscle Interface: creeping fat influencing stricture formation in Crohn's disease. Inflamm Bowel Dis. 2019;25(3):421-6.

93. Coffey CJ, Kiernan MG, Sahebally SM, Jarrar A, Burke JP, Kiely PA, et al. Inclusion of the mesentery in lleocolic resection for Crohn's disease is associated with reduced surgical recurrence. J Crohns Colitis. 2018;12(10): 1139-50.

94. de Groof EJ, van der Meer JHM, Tanis PJ, de Bruyn JR, van Ruler O, D'Haens $\mathrm{G}$, et al. Persistent Mesorectal inflammatory activity is associated with complications after Proctectomy in Crohn's disease. J Crohns Colitis. 2019; 13(3):285-93.

95. Li Y, Mohan H, Lan N, Wu X, Zhou W, Gong J, et al. Mesenteric excision surgery or conservative limited resection in Crohn's disease: study protocol for an international, multicenter, randomized controlled trial. Trials. 2020; 21(1):210

96. Sakuraba A, Sato T, Kamada N, Kitazume M, Sugita A, Hibi T. Th1/Th17 immune response is induced by mesenteric lymph node dendritic cells in Crohn's disease. Gastroenterology. 2009;137(5):1736-45.

97. Sathaliyawala T, Kubota M, Yudanin N, Turner D, Camp P, Thome JJC, et al. Distribution and compartmentalization of human circulating and tissueresident memory T cell subsets. Immunity. 2013;38(1):187-97.

98. Masopust $D$, Schenkel JM. The integration of T cell migration, differentiation and function. Nat Rev Immunol. 2013;13(5):309-20.

99. EuroSurg C. EuroSurg: a new European student-driven research network in surgery. Colorectal Dis. 2016;18(2):214-5

\section{Publisher's Note}

Springer Nature remains neutral with regard to jurisdictional claims in published maps and institutional affiliations.

Ready to submit your research? Choose BMC and benefit from:

- fast, convenient online submission

- thorough peer review by experienced researchers in your field

- rapid publication on acceptance

- support for research data, including large and complex data types

- gold Open Access which fosters wider collaboration and increased citations

- maximum visibility for your research: over $100 \mathrm{M}$ website views per year

At BMC, research is always in progress.

Learn more biomedcentral.com/submission 